\title{
Las voces del aire: la radio y la construcción de un nuevo espacio de negociación en el Perú (1925-1930)
}

\section{Voices in the air: radio and the construction a new medium for negotiation in Peru (1925-1930)}

Juan Chumpitaz Fernández ${ }^{1}$

Pontificia Universidad Católica del Perú, Universidad Nacional Federico Villarreal

Lima, Perú

juanadriano@hotmail.com

\section{RESUMEN}

La aparición y el desarrollo de la tecnología de la radio, en las primeras décadas del siglo XX, motivaron los intereses de los gobernantes de los Estados sudamericanos, entre ellos el Perú, en utilizarlo como un medio de difusión de los valores nacionales en función de los intereses políticos. En este contexto y cercanos al plebiscito de 1929, que decidió la suerte de Tacna y Arica, se construyó un nuevo espacio de negociación y, tras un breve periodo de control del medio por parte de grupos de aficionados y particulares, la producción radial pasó a ser controlada por el Estado en el auge del Oncenio, mediante la creación de una emisora de radio, la Radio Nacional, como institución estatal. Ello obligó a elaborar una programación de emisiones radiales de carácter nacional que permitieran construir una identidad ciudadana y un nuevo consumidor como parte del proyecto modernizador del Estado.

\section{PALABRAS CLAVE}

Radio, nacionalismo, Patria Nueva, ciudadanía

\footnotetext{
1 Licenciado en Historia por la Universidad Nacional Federico Villareal. Magíster en Historia por la Pontificia Universidad Católica del Perú. Docente de la Universidad Nacional Federico Villareal y de la Universidad Tecnológica del Perú. Directivo de la Asociación de Inventores del Perú, inventor, tecnólogo e investigador especialista en historia de la tecnología y la ciencia. Ha realizado trabajos sobre la invención y la tecnología en el Perú de los periodos colonial y republicano. Ganador del Primer Concurso de Tesis Universitaria en Historia Económica de la Asociación Peruana de Historia Económica.
} 


\section{ABSTRACT}

The emergence and development of new radio technology, during the first decades of the twentieth century, awoke interest among the rulers of South American countries, including Peru, who saw it as a means of popularizing national values founded upon political interests. In this context, and on the eve of the 1929 plebiscite which would decide the fate of Tacna and Arica, a new medium for negotiation emerged, and following a brief period of control on the part of amateurs and individuals, radio production would be controlled by the state during the Oncenio period, through the creation of the radio station Radio Nacional as a public institution. This took the form of radio broadcasts with an emphasis on national character, designed to encourage the development of a civic identity and a new consumerism, as part of the state's modernization project.

\section{KEYWORDS}

Radio, nationalism, New Homeland, citizenship

\section{Introducción}

En la segunda década del siglo XX, la naciente tecnología de la radio despertó el interés de gobernantes como Augusto $B$. Leguía, quien rápidamente comprendió su potencial social y su importancia política, y la sustrajo del primigenio control de radioaficionados y particulares, mediante su conversión, gracias al control estatal, en un instrumento de construcción de una identidad nacional frente al cercano plebiscito de 1929 y en un dinámico nuevo espacio de negociación política y social bajo el impulso de la Patria Nueva (Klaren, 2012).

El uso político de la radio - y la construcción de un discurso radial nacional- por parte del régimen de Leguía llevó a la creación de una emisora de radio en 1926, sobre la base de la Peruvian Broadcasting Co. (primera estación que emitió una señal de radio comercial en el Perú, establecida en 1925 como un proyecto empresarial privado), esta vez supeditada al control estatal y de acuerdo con los fines políticos del Oncenio. Esta emisora sustraía su frecuencia radial de aquellas usadas por las bandas de radioaficionados, entre quienes deben incluirse a los que habían construido o comprado sus equipos (receptores y transmisores) utilizando partes, esquemas y diagramas constructivos de diferentes procedencias.

Al respecto, cabe formularnos las siguientes interrogantes: ¿cómo recibió la población urbana este nuevo medio? ¿Se convirtió en un medio de 
entretenimiento, de difusión de noticias o de reproducción de modelos identitarios nacionales por parte del Estado? ¿Se fortalecieron los lazos de identidad nacional y de lealtad ciudadana entre los consumidores urbanos y provincianos?

El éter se convirtió en el nuevo espacio de negociación, pero la comunicación estaba limitada por factores culturales, técnicos y geográficos, como las características de la superficie terrestre, especialmente difíciles debido a la especial conformación geográfica del relieve peruano. Este nuevo espacio fue originalmente un fenómeno urbano, bajo cuyo estímulo se crearon, poco tiempo después, estaciones y programas de radio provincianas. Este primer periodo de la radio en el Perú estuvo dominado por las emisiones en onda larga. Posteriormente, se inició la transición hacia las ondas medias y se dejaron las ondas cortas dedicadas para la comunicación a gran distancia.

La creación de un espacio donde los ciudadanos se convierten en consumidores - los radioyentes - incentivó la adquisición (y la fabricación por parte de los aficionados) de los primeros equipos radiofónicos de uso doméstico y de los elementos de su correspondiente familia tecnológica (Maskrey y Rochabrún, 1990) (antenas, baterías, válvulas electrónicas, tomacorrientes, tomas de tierra, etc.). Asimismo, fomentó la aparición de los primeros centros de reparación, asistencia técnica y mantenimiento, y de las primeras escuelas técnicas formadoras de especialistas en el mantenimiento, la reparación y el uso de la nueva tecnología. La compra de los primeros aparatos receptores comerciales por parte de los consumidores se convirtió, además, en sinónimo de estatus y modernidad.

\section{El paradigma radial}

Los rápidos avances técnicos de comienzos del siglo XX ampliaron las posibilidades de la radio como un medio de comunicación no solo de aplicaciones y usos militares, sino también civiles. Ya en la Primera Guerra Mundial se había generalizado el uso de la comunicación inalámbrica (Equipo Fénix, 1996, p. 14) entre los ejércitos y armadas de los países en conflicto.

En 1906, se descubrió que algunas sustancias minerales como la galena, un sulfuro de plomo, tenían la capacidad de detectar las transmisiones radiales mediante el uso de circuitos simples y sencillos de construir, lo que dio origen al receptor de cristal. Entre los primeros radioaficionados se difundió prontamente un circuito básico, de receptor de cristal de galena (comprado o elaborado localmente), que contaba con una gran ventaja: podía ser elaborada con materiales fácilmente asequibles. Estos primitivos receptores, básicamente detectores de ondas de radio sin 
capacidad de amplificación y de muy pobre selectividad, se podían fabricar de acuerdo con un esquema constructivo basado en una sencillez mecánica y eléctrica cuya fiabilidad pregonaba El Comercio de Lima en 1925:

no se malogra fácilmente, se lleva por todas partes, pues no requiere batería de ninguna clase para funcionar. Basta adherir un par de fonos a dos de los bornes y colocar los más rudimentarios hilos de antena y tierra para que [...] comience a revelar los discursos y la música, los datos oficiales, las referencias al tiempo, las noticias sensacionales y los anuncios, siempre que alguna estación trasmisora los haya puesto ya en el aire (EI Comercio, 20 de febrero de 1925, p. 5).

Aun operando bajo estas condiciones, los primeros radioaficionados debían establecer manualmente el punto de detección del cristal de galena, engorrosa parte crítica de la recepción, por medio de un resorte que terminaba en una fina aguja metálica o «bigote de gato»². La parte más aguda de este implemento reposaba en la superficie de un cristal semiconductor hecho a base de sulfuro de plomo o galena. Luego, se procedía a sintonizar manualmente una emisora (Orton, 2006, p. 22), mediante la variación de un capacitor de aire o de la inductancia de una bobina.

El receptor de galena, si bien no poseía la capacidad de amplificar la señal audible a causa de las bajas corrientes obtenidas por la señal detectada, que solo permitía el uso de transductores de alta impedancia o de auriculares de cristal, hizo posible que surgiera entre el público interesado en las posibilidades de la nueva tecnología «un verdadero ejército de entusiastas por la nueva ciencia. A los muchachos le siguió rápidamente toda la familia, de suerte que para 1920 estaban dados los antecedentes que harían posible el inicio de la radiodifusión» (Anda y Ramos, 1997, pp. 46-47). Los rudimentarios equipos solo requerían para funcionar un trozo de cristal de sulfuro de plomo que podía ser elaborado en casa a partir de una simple mezcla de azufre y plomo pulverizados y sometidos a la acción del calor, algunos auriculares de alta impedancia, de una cierta cantidad de alambre de cobre y de cierta destreza manual, por lo que «podían ser construidos con poco gasto por cualquier persona que tuviera una habilidad mecánica elemental» (Anda y Ramos, 1997, p. 46). Sin embargo, los manuales y libros técnicos eran aún escasos ${ }^{3}$ y los primeros aficionados se contentaban con los pocos ejemplares que llegaban al Perú, en su mayor parte procedentes de Estados Unidos y Argentina. Entre ellos, destacaba la revista

2 En referencia al trozo de alambre, generalmente con ayuda de un resorte, en contacto con la superficie del cristal de galena

3 La revista estuvo orientada especialmente al radioaficionado: «magazine - a 100\% radio magazine-, by and for the amateur. Ifelt that a magazine for the entire radio fraternity, be he scientist, advanced, or junior amateur». Gernsback, 1919, p. 5. 
Radio News, editada por Hugo Gernsback ${ }^{4}$, una de las primeras publicaciones dedicadas al radioaficionado amateur que circuló en Sudamérica.

En 1908, la estación construida por Charles Herrold comenzó a emitir, de manera regular, información meteorológica privada destinada a los campesinos de California (Equipo Fénix, 1996). En 1920 se puso en funcionamiento la primera emisora con programación regular del mundo: la estación KDKA de Pittsburg y, hacia 1925, la emisión de noticias fue el tipo de programa radial más difundido en las estaciones de radio.

Para el decenio de 1920, la radio como medio se desarrollaba rápidamente gracias al uso de las primeras válvulas termoiónicas comerciales, que desplazaron a los sencillos circuitos detectores de los primeros años, y terminaron estableciéndose «definitivamente con la supremacía del bulbo sobre otros tipos de generadores o detectores» (Anda y Ramos, 1997, p. 47). La recepción y la selectividad fueron mejorándose continuamente y se pasó de los primitivos circuitos a base de cristal de galena a receptores con mayor selectividad y capacidad de amplificación, equipados con las primeras válvulas termoiónicas: los audiones, dispositivos inventados y comercializados por Lee De Forest, que, en esencia, derivaban de las válvulas diodos inventadas algunos años antes por J. A. Fleming ${ }^{5}$, asesor científico de la compañía Marconi. A estos siguieron los receptores regenerativos, rápidamente desplazados por los receptores heterodinos y superheterodinos, que permitían una mayor selectividad de las emisoras (De Fleur, 1976, p. 92). De esta manera, quedaron definidas la forma y la función predominante de la radio en los siguientes decenios:

La «caja de música radiotelefónica» estaría provista de bulbos amplificadores y un altoparlante, todo ello prolijamente acondicionado en la misma caja. Ubicada sobre una mesa en la sala o en la estancia, haciendo girar la perilla se escucharía la música trasmitida (Anda y Ramos, 1997, p. 45).

Siguiendo tal descripción, un elemento indispensable e icónico que hace su aparición en este periodo es el dial o cuadrante de emisoras, elemento distintivo de los aparatos radiofónicos analógicos, unido mecánicamente a un circuito formado por un condensador variable y acoplamiento capacitivo, inventados por Charles S. Franklin mientras trabajaba para la compañía Marconi.

4 Véase: Gernsback, 1919, y Gernsback, 1922. Fue el editor de la primera revista de electrónica: Modern Electric, aparecida en 1908.

5 J. A. Fleming, inventor de la válvula diodo, trabajó en la compañía Marconi, establecida en julio de 1897 como Wireless Telegraph and Signal Co. Ltd. En 1900, la empresa cambió su nombre a Marconi Wireless Telegraph Co. El término diodo fue creado por William Henry Eccles. 
La aparición de las primeras válvulas triodo hizo posible la amplificación de las débiles señales de los primeros receptores y la aparición del transductor ${ }^{6}$ de salida o parlante de bobina móvil y núcleo (inducido o magnético), que reemplazaron a los transductores de difusor magnético (Lagoma, 1974, p. 172) del periodo primigenio de la radio. A ello se debió que la recepción de los primeros programas radiales ${ }^{7}$ se vinculara a la esfera doméstica y pública. Por lo tanto, las condiciones que permitieron la aparición de la radio fueron el resultado del continuo desarrollo de los aparatos de transmisión y recepción y de sus correspondientes familias tecnológicas, que fueron cambiando los modos sociales de uso ${ }^{8}$ del nuevo dispositivo técnico.

La creación del paradigma radial responde a los lineamientos concebidos por David Sarnoff en 1916, entonces vicepresidente y gerente general de la compañía American Marconi, que algunos años más tarde se convertiría en la RCA Radio Corporation of America, previendo la utilidad pública comercial y utilitaria del nuevo medio de comunicación`. El plan propuesto por Sarnoff serviría para convertir a los radiorreceptores «en un elemento de esparcimiento hogareño como el piano o el fonógrafo. La idea consiste en llevar la música a los hogares mediante la transmisión inalámbrica» (De Fleur, 1976, p. 93). Las limitaciones de la transmisión telegráfica clásica, es decir, los hilos de alambre, se superarían mediante la instalación de radiotransmisores convenientemente ubicados y:

con un alcance promedio comprendido entre los 40 y 80 kilómetros en un lugar determinado en que se produciría música instrumental o vocal o de ambas clases [...] Al receptor podría dársele la forma de una sencilla "caja de música radiotelefónica», adaptándolo a varias longitudes de onda de modo que pudiera pasarse de una a otra con solo hacer girar una perilla o apretar un botón (De Fleur, 1976, pp. 92-94).

6 El sonido reproducido por medio de un transductor de salida o parlante, es el paso final de la emisión radial que permite una «relación existencial entre sonido y fuente o voz e individuo» (Fernández, 2008, p. 17).

7 «[E]l sonido es siempre proporcional a la energía eléctrica suministrada [...] El primer medio que se utilizó para la conversión o traducción de la corriente musical en sonidos o energía acústica fueron los llamados auriculares» (Lagoma, 1974, p. 171).

8 "Cuando aquí se hace referencia a la noción de dispositivo técnico se remite, pues, al conjunto de mecanismos técnicos que permiten la comunicación de voz a distancia a través de las ondas de radio. Pero además, en el caso de la radio, el problema del dispositivo técnico no debe circunscribirse a los principios técnicos de la institución radiofónica (Gutiérrez Reto, 2008, p. 94).

9 Sarnoff percibiò la utilidad y los alcances del nuevo medio no solo «para transmitir y recibir música, sino también para difundir conferencias, eventos públicos especiales, marcadores de béisbol y muchos otros temas de interés popular» (Anda y Ramos, 1997, p. 44). 
De esta manera, quedaron definidas las formas, funciones básicas y características estéticas de los radiorreceptores comerciales domésticos que predominaron durante todo el resto del siglo XX.

Hacia la década de 1950, el uso de los conversores a batería y de válvulas especiales posibilitó el uso de radiorreceptores en los automóviles. Estos aparatos no precisaban estar conectados a la red eléctrica - virtualmente inexistente en los pueblos y ciudades del interior del país- para funcionar, lo que permitía una mayor ampliación y difusión de los servicios radiales y su asociación al ideal de modernidad.

\section{La construcción de lo auditivo}

El fonógrafo, el gramófono y el teléfono, desarrollados en el último cuarto del siglo XIX, fueron, junto al telégrafo, los medios de comunicación que antecedieron a la aparición de la radio ${ }^{10}$ y sociabilizaron los nuevos medios de comunicación ${ }^{11}$. El telégrafo Morse fue el primer medio de comunicación introducido en el Perú en el siglo XIX, aunque no transmitía el sonido, sino una codificación de puntos y rayas. Sin embargo, «[e]l telégrafo y el teléfono se deben considerar como uno de los antecedentes tecnológicos e industriales directos de la radiodifusión» (Anda y Ramos, 1997, p. 24), y formaron parte del proyecto modernizador del siglo XIX.

Fonógrafos y gramófonos de los más afamados fabricantes se vendían en Lima a fines del siglo XIX y prepararon el escenario propicio para la introducción de la radio: «El fonógrafo primero y el gramófono después ya habían creado el hábito de escuchar música» (Anda y Ramos, 1997, pp. 2324). Comerciantes e importadores de fonógrafos, como la Casa Bacigalupi de Lima, representante de los fonógrafos de la Casa Edison que utilizaban cilindros de cera, prepararon al público limeño para la llegada de la radio.

Los fonógrafos de cilindros Edison y los fonógrafos Berliner de disco plano, vendidos como fonógrafos de gabinete, permitieron su introducción en los hogares y espacios sociales. Cada uno garantizaba ser cada uno ser el «más fiel reproductor de la voz humana» (El Comercio, 6 de febrero de 1925, p. 9) y prometía al usuario la mayor fidelidad musical. En Lima, la Casa Zoffner promocionaba, en 1925, la calidad de los fonógrafos Sonora y los presentaba como un novedoso artefacto que, a diferencia de otros, «no grita ni chilla» (El Comercio, 19 de febrero de 1925), en respuesta a la distorsión sonora originada con el desgaste mecánico por la fricción de la aguja contra la superficie del disco.

10 «La radio es un medio de comunicación tan joven y actual como pueda serlo el cine o la televisión» (Equipo Fénix, 1996, p. 12).

11 «Los usos sociales de los nuevos medios de comunicación modificaron gradualmente la experiencia de oír música» (Fernández, 2008). 
Entre los primeros artistas locales ${ }^{12}$, cuyas canciones fueron popularizadas mediante las grabaciones fonográficas y los discos de carbón, destaca el afamado dúo de música criolla Montes y Manrique ${ }^{13}$. Las primeras grabaciones y registros fonográficos de Montes y Manrique datan de 1911. Ellos fueron, también, los primeros artistas peruanos cuyas canciones y composiciones fueron emitidas en las primeras programaciones radiales.

\section{La construcción de lo radiofónico}

En este periodo se produjo el cambio tecnológico de los receptores de galena hacia los receptores regenerativos, desplazados, en pocos años, por los receptores heterodinos y superheterodinos. El concepto de radiofonía se construyó en el periodo comprendido en el primer lustro de los años 20: «En términos generales, hay acuerdo en que en el periodo 1920-1935 se construye eso que denominamos como lo radiofónico y se produce el pasaje de una sociedad sin radio a una sociedad con radio» (Fernández, 2008, p. 36). La aparición de las primeras válvulas termoiónicas al vacío comerciales permitió la fabricación y comercialización de los primeros receptores a válvulas, cuyas primeras series y modelos utilizaban los audiones elaborados y vendidos por la empresa de Lee De Forest. Los primeros receptores comerciales a válvulas utilizaban los frágiles audiones tipos 32 y 33, que eran, en esencia, válvulas triodos. Por lo tanto, los fabricantes y los distribuidores comercializaban los radiorreceptores por la cantidad de tubos o válvulas que incluían, a despecho de las series.

Contribuyen en la construcción de lo radiofónico el telégrafo, que enviaba mensajes en series de puntos y rayas; el código Morse, la telegrafía sin hilos o radiotelegrafía, con la capacidad de enviar código Morse. Este desarrollo tuvo un gran impulso cuando se comprobó que se podía enviar información audible montada en una onda portadora y, a su vez, que esa onda de radio podía ser sintonizada y detectada. Un circuito detector separaba la señal portadora, modulada en amplitud, de la señal de audio, que, dependiendo de su capacidad de amplificación, sería luego aplicada a un amplificador y un transductor de salida o conectado a unos sencillos auriculares de uso personal:

A esta altura, hablar de la construcción de lo radiofónico implica poco más que advertir que nos referimos a un proceso complejo que,

12 «El fonógrafo Introdujo cambios muy importantes en los usos y costumbres de las clases medias y altas» (Anda y Ramos, 1997, p. 23).

13 En Nueva York, contratados por la casa comercial Holding, Eduardo Montes y César Manrique grabaron 172 canciones de música criolla, marineras, valses, y tonderos, que representan los gustos de la población limeña, y no necesariamente nacional, de principios del siglo XX. 
desde el punto de vista anterior, mientras se desarrolla ese medio que la sociedad va a denominar y consumir como radio, incluye varias series de fenómenos: dispositivos técnicos que se van incorporando al uso radiofónico generando posibilidades y restricciones de construcción discursiva, géneros y estilos radiofónicos que van a ir apareciendo y consolidándose y lo mismo va a ocurrir con prácticas sociales nuevas - total o parcialmente, directa o indirectamenterelacionadas con el nuevo medio» (Fernández, 2008, pp. 35-36).

En el periodo comprendido entre 1925 y 1937, la radio, gradualmente, se convertirá de «un medio de élite a uno de masas» (Bustamante Quiroz, 2012, p. 33). Por lo tanto, la construcción de lo radiofónico en el Perú ${ }^{14}$ se realiza en un contexto tecnológico dinámico, que se inserta en el proyecto de modernización del Estado peruano de régimen leguiista, que colocaría al Perú al mismo nivel de los demás países sudamericanos, tomando como ejemplo el impulso dado por Estados Unidos, país «por entero entregado a especulaciones científicas, mercantiles, sociales y artísticas, cuyos beneficios no pudieron sospecharse cuando Herz, Bradley, Lodge, Ricci, De Forest y Marconi se engolfaban en los maravillosos experimentos que hoy han puesto al hombre en comunicación instantánea de un lugar a otro de la Tierra» (El Comercio, 12 de febrero de 1925, p. 5). La radio, como símbolo de modernidad y de inclusión en la dinámica de la tecnología y la política de principios del siglo XX, se incluye, entonces, bajo este modelo, en el proyecto leguiista de la Patria Nueva.

En 1925, un anuncio de casi página completa, publicado en El Comercio de Lima (El Comercio, 1 de febrero de 1925, p. 12), presentaba al público la novísima «técnica radiotelefónica» y se explicaba y presentaba las características de la nueva tecnología de los «aparatos radiofónicos», a fin de familiarizarlos al público con los misterios de este nuevo artículo doméstico:

Son muy numerosos y de muy variado merito los tipos de aparatos existentes. Uno de los receptores más perfectos es el R.E. 2, fabricado por la sociedad anónima Afra (Radiomuseum, s. f.), de forma elegante, manipulación sencilla y excelente reproducción. La música y la voz son reproducidas muy clara y distintamente aun a gran distancia. La caja del aparato es de reducidas dimensiones. La tapa frontal es de caucho $y$, en su parte superior, a la derecha, se hallan los contactos para unir el aparato a las baterías, de manera que no puedan confundirse los polos. Debajo se hallan tres pares de contactos para tres

14 «En términos generales, hay acuerdo en que en el periodo 1920-1935 se construye eso que denominamos como lo radiofónico y se produce el pasaje de una sociedad sin radio a una sociedad con radio» (Fernández, 2008, p. 37). 
pares de auditores. Dos discos giratorios $\mathrm{P}$ y $\mathrm{Z}$ sirven para graduar los círculos primario e intermediario. A la izquierda se encuentran tres tornillos de contacto, A, E, y E1, para la antena y el contacto terrestre. Para aumentar la intensidad de los sonidos a gran distancia, y si se conecta un altoparlante, se emplea un dispositivo de baja frecuencia con dos tubos, que no se une con alambres, sino colocando el receptor encima del altoparlante (Radiomuseum, s. f.).

Estas primeras emisiones eran monoaurales, en las que el espectro de sonido no se encuentra separado en canales independientes. Pasaron dos décadas antes de la introducción de la modulación por frecuencia (FM), que permitió llevar la señal sonora estereofónica inclusa en su onda portadora. La radiodifusión planteó un problema social y económico; especialmente a la industria disquera, «la cual hacia 1933 estaba casi extinguida. Se hizo necesaria una revolución tecnológica para que los fonogramas aprovecharan el creciente interés por la música que estaba creando desde sus inicios la radiodifusión» (Anda y Ramos, 1997, pp. 23-24), tal como en su momento lo hizo la aparición del fonógrafo respecto a los músicos.

Entre 1923 y 1924, aparecen los receptores Stromberg Carlson, ofrecidos en Lima por su representante, la Peruvian Broadcasting. En 1925, el modelo 1a (Radiola Guy, s. f.) costaba 295 dólares en Estados Unidos (Steven Johannessen Antique Radio Gallery, s. f.). El aparato se vendía sin altavoz (pero podía utilizar uno del tipo corneta, que se vendía con un costo adicional de 275 dólares) e incluía las clavijas para conectar los auriculares, al igual que la mayoría de los receptores de la época, y, como ellos, era un receptor neutrodino. Solo los fabricados por la empresa De Forest poseían un pequeño parlante en la caja. Los aparatos vendidos en Lima eran aún muy caros en relación con el salario medio de un obrero, en una época en la que «un bistec costaba 10 centavos de sol y la Peruvian Broadcasting vendía a 30 soles cada aparato y a 10 soles la instalación de la antena» (Alegría, 2008, p. 34). Ruiz (2001) describe cómo, a partir de una encuesta realizada en 1918, «las familias obreras destinaban el $65 \%$ de sus gastos para la alimentación y un $10 \%$ se iba en pagar el alquiler de la habitación en los barrios populares de la ciudad» (Ruiz Zeballos, 2001, p. 177). Como referencia, el jornal de un operario adulto de sastrería en 1919 era de 4,5 soles.

En el diario El Comercio de Lima, el 20 de febrero de 1925, se ofrecía al público una alternativa más económica: la posibilidad de construir un pequeño y sencillo receptor de galena, que fue promocionado como «el receptor de cristal que cabe en una mano» (El Comercio, 20 de febrero de 1925). Para los aficionados y el ciudadano común sin capacidad de adquirir los nuevos receptores ofrecidos por la Peruvian Broadcasting, comenzó 
una búsqueda intensa de cables, alambres y partes diversas por las ferreterías de Lima. En el caso de no conseguir los accesorios principales, solo quedaba la posibilidad de adquirir las piezas y partes directamente de la empresa monopolizadora del nuevo medio, naturalmente ofrecidas por la entonces $\mathrm{OAB}$, que promocionaba las ventajas del receptor, su fácil manejo (figura 1) y sus posibilidades:

Toda la base está hecha de ebonota ${ }^{15}$ [sic], moldeada en forma para ocultar y defender la inductancia (arrollamiento de alambres) que hay en el interior. Para oponerse a tono con la estación trasmisora, basta mover el muelle que se divisa junto al dedo pulgar de la mano que sostiene el aparato. Ese muelle corre por la ranura, que es la línea oscura que va de derecha a izquierda, y mediante ese movimiento se pone en circuito mayor o menor cantidad de alambre. Los bornes destinados a la antena y tierra están a la derecha y los que corresponden a los fonos a ala izquierda. Al centro está el detector. Abajo el recipiente para el cristal, que es un trocito de galena (sulfuro de plomo) y arriba el pivote que actúa el muelle o pequeña espiral de alambre que hace contacto.

Todas esas partes están defendidas del polvo y del contacto de los dedos por un pequeño cilindro de vidrio (EI Comercio, 20 de febrero de 1925).

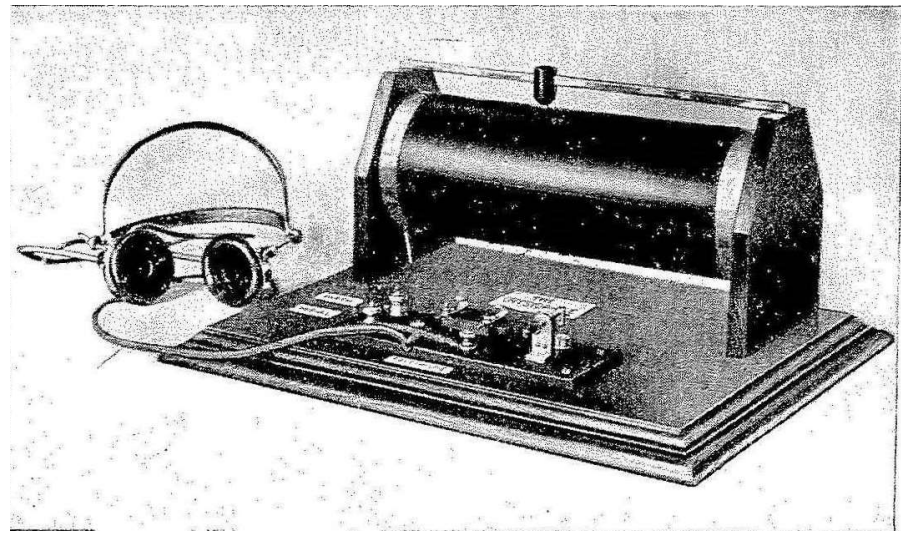

FIGURA 1. El Crystophone, una radio a galena similar a la ofrecida por la Peruvian Broadcasting. Tomado de Harris, 1922, p. 23.

Los primeros radioaficionados peruanos, tal como sus pares extranjeros, eran básicamente telegrafistas no profesionales o «morsistas amateurs», pues las señales se enviaban en código Morse (Gargurevich, 1995). En 1904, la empresa Electro Importing Co., de Nueva York, vendía partes

15 Ebonita, uno de los primeros polímeros a base de azufre y caucho. 
y accesorios para los radioaficionados. Hacia 1908, se realizaron comunicaciones telegráficas entre el Pacífico y el Atlántico, siguiendo el modelo de la American Radio Relay League y motivados por la difusión de Modern Electric, la primera revista especializada en radiotelegrafía, editada por Hugo Gersback ${ }^{16}$. En 1910, la empresa Telefunken fundó la primera instalación de telegrafía sin hilos de Lima en el cerro San Cristóbal. El siguiente paso fue la radiotelefonía, y los «aficionados a escuchar y que procuraban conseguir los mejores receptores, de los que transmitiría además de escuchar. Fueron estos los que se agruparon en tertulias a partir de 1924 y decidieron fundar un club, al estilo de sus colegas de los países del norte» (Gargurevich, 1995, p. 61). Con estos antecedentes, el primer radioclub peruano se creó en 1925 bajo el auspicio de la estación OAX de la Peruvian Broadcasting, que ofrecía a los aficionados un descuento de $10 \%$ en aparatos y modelos fabricados por la Casa Stromberg Carlson, y partes y piezas de repuesto para los primeros receptores comerciales superheterodinos de mayor selectividad.

\section{La radio y el proyecto leguiista}

El jueves 12 de febrero de 1925, se anunciaba al público limeño la construcción e instalación de los equipos, generadores eléctricos, y la pronta emisión de la señal radial en las instalaciones de la Compañía Peruana de Broadcasting, cuya estación transmisora llevaba originalmente la cifra radioeléctrica $\mathrm{OAB}$, y poco después será definitivamente OAX (Vargas Escalante, 1944), en su local ubicado «en la calle de Washington. Es un buen espacio donde se han levantado las habitaciones destinadas a instalar los generadores, rectificadores y transmisores de la instalación radiotelefónica» (El Comercio, 12 de febrero de 1925, p. 5).

Construir un proyecto nacional con modelos culturales musicales fue un modo de educar a la población para solidificar un modelo identitario de nación sobre la base de una «peruanidad», que se manifestaba en la existencia de una negociación en la creación de un patrón o paradigma de la cultura nacional. Era un paso necesario frente a la proximidad del plebiscito con Chile y su proceso de consolidación de un Estado nacional mediante la chilenización de lo que se llamó el «norte grande»; es decir, el antiguo sur peruano, cuya mayor cantidad de residentes eran efectivamente peruanos ${ }^{17}$. Como no le fue posible lograr una homogenización

16 En 1922, Gersback publicó Radio for All, un libro que incluía diagramas y planos para los aficionados.

17 «Esta historia de nacionalismo compulsivo comienza a escribirse hacia 1910, con la expulsión de los curas peruanos en las provincias ocupadas por Chile, lo que tuvo como consecuencia la ruptura de relaciones diplomáticas entre ambos países. 1910 era el año del centenario en Chile y el nacionalismo era un sentimiento que emergía desde todos los rincones y 
étnica sin la expulsión de los peruanos de Tarapacá, el Estado chileno procedió a su homogenización cultural mediante el uso velado de la coerción y la violencia. La homogenización étnica fue un modelo de consolidación del Estado nacional ${ }^{18}$, que tomará fuerza desde fines del siglo XIX y se evidenció, incluso, en los años posteriores a la Segunda Guerra Mundial.

De acuerdo con Gargurevich (Gargurevich, 1995), el proyecto leguiista adoptó el paradigma norteamericano de radiodifusión e incorporó a la radio como parte del proyecto político del Oncenio; «siendo como son tan sencillos los medios de manejar ese aparato, seguramente el público se encariñará pronto con él» (El Comercio, 20 de febrero de 1925). Se tomó como eje una ciudad que hacia 1931 llegó a ocupar más de 2000 hectáreas, una ciudad en vías de tugurización, pero «fuera de Lima, en el conjunto del país. Lo rural seguía predominando sobre lo urbano» (Bustamante Quiroz, 2012, p. 15). Pese a las tempranas limitaciones técnicas y comerciales ${ }^{19}$, y vistas sus potencialidades, la radio fue utilizada como un medio, un vehículo para la construcción de una identidad nacional, en un contexto de problemas internacionales. Era urgente la cuestión de Tacna y Arica.

Sostenemos que, pese a la intención de Leguía de construir la radio en el Perú como parte del proyecto político del Oncenio, en un nuevo medio para la Patria Nueva (Bustamante Quiroz, p. 2012, p. 29), elementos de inicial carácter técnico, económico, lingüístico y social, limitaron su expansión temprana nacional, y fue inicialmente un proyecto de carácter urbano y criollo, a cuya semejanza se irán construyendo los proyectos de radiodifusión provincial (Oyarce, 2007).

Leguía convirtió a la naciente radio peruana en un monopolio privado y advirtió tempranamente su uso político y su influencia mediática, de tal manera que advertimos, a partir de la década de 1920, la intensa relación entre la radio y la política. El régimen de Leguía aprovechó la radio para defender a través de sus ondas «su postura en torno al plebiscito sobre la devolución de Tacna y Arica al Perú» (Bustamante Quiroz, 2012, p. 34). Al quebrar tempranamente la Peruvian Broadcasting, el régimen de Leguía lo entregó al control de la Empresa Marconi.

La radio al servicio del proyecto político leguiista tenía un antecedente temprano: el 21 de junio de 1923, Warren Harding se convirtió en el primer

sectores sociales como un manantial natural» (González Miranda, 2004, p. 9).

18 En Europa permanecerán poblaciones de diverso origen étnico que representan el problema de la fidelidad al Estado nacional.

19 «Cuando en 1925 Augusto B. Leguía inauguró la primera estación radiodifusora, OAZ, eran muy pocos quienes podían comprar en el Perú un receptor, aunque algunos armaban ingeniosamente sus propios aparatos de galena. Diez años después, la radio estaba ya en camino de convertirse en un medio de masas» (Bustamante Quiroz, p. 2012, p. 29). 
presidente de Estados Unidos en utilizar la radio (Equipo Fénix, 1996) y las primeras programaciones radiales para promocionar su carrera política. En Latinoamérica, si bien no fue el primero, el 3 febrero de 1925 el cónsul argentino presentó por intermedio de una estación de radio ubicada en Londres un discurso transmitido por las estaciones de Broadcasting. Ello aumentaría la confianza del régimen de Leguía en el poder propagandístico de la radio (Bustamante Quiroz, 2012, p. 22), a pesar del uso político y la «rutina y baja calidad de [la] programación» (Bustamante Quiroz, 2012, p. 22) del sistema radial que solo cambiaria al caer el régimen de Leguía.

Los primeros radioaficionados peruanos, que, al igual que sus colegas en el mundo, construían sus propios aparatos a base de guías, manuales y esquemas publicados en revistas especializadas, operaban inicialmente y principalmente con transmisores y receptores comprados o construidos localmente a partir de «un cristal de galena, las emisiones que hacían los radioexperimentadores y algunas empresas industriales. Los radios de galena podían ser construidos con poco gasto por cualquier persona que tuviera una habilidad mecánica elemental» (Anda y Ramos, 1997, p. 46). En 1925, se anunciaba en El Comercio que la compañía Peruvian Broadcasting iniciaría «en breve la venta de sus aparatos de recepción, de partes para formarlos, repuestos y baterías. Ha establecido sus oficinas y lugar de venta en la calle de divorciadas» (El Comercio, 20 de febrero de 1925). Para los primeros radioaficionados se presentó la posibilidad de construir sus equipos receptores con partes y piezas de diversas procedencias, algunas de la cuales podían encontrarse fácilmente en las ferreterías y comercios de Lima. La Peruvian Broadcasting garantizaba que, gracias a su nuevo y potente transmisor, su señal se podría captar aún en los sencillos receptores de galena:

Fuera de la capital, seguramente se podrán escuchar sin dificultad las trasmisiones de la estación de Lima OAX en los departamentos de La Libertad, Áncash, Huánuco, Junín, Huancavelica e Ica; y empleando receptores complicados y en condiciones sumamente favorables, en todo el territorio comprendido entre los grados 4 y 16 sur del ecuador (El Comercio, 12 de febrero de 1925).

De acuerdo con la cita anterior, las emisiones radiales comenzaron a efectuarse desde Lima. La primera emisión pública de la recién creada Peruvian Broadcasting Company, después de tres ensayos, culminó con la primera emisión de «cantos nacionales acompañados en la guitarra por Montes y Manrique (nada menos). Es la primera vez que se transmite música peruana» (Alegría, 1988, p. 26), y la instalación de un altoparlante en la plaza San Martín para una demostración pública del nuevo espacio de negociación que promovía un nacionalismo musical (Turino, 2003, p. 178), 
tomando como referencia inicial la música criolla limeña ${ }^{20}$. En las salas y teatros, los patrones musicales estaban caracterizados por la disposición del público oyente, que correspondía a su disposición espacial y social en la ciudad: «En el centro, cuyo radio es pequeño, se halla la clase acomodada; el público que se quiere extranjerizar, el que fomenta los conciertos, las tertulias, los bailes de fantasía, las veladas» (Gamarra, 1907, p. 4). Entre la segunda mitad de la década de 1920 y finales de la de 1930, «brillaban las primeras estrellas [de la radio] y la música criolla empezaba su reinado en el dial» (Bustamante Quiroz, 2012, p. 29), lo que consolidaba el imaginario colectivo de una música nacional peruana.

La creación de una radio nacional en 1926, sobre la base de la Peruvian Broadcasting Co., fue parte del proyecto de modernización del régimen de Leguía, en el que la radio representó para el Oncenio ${ }^{21}$ el elemento básico en la construcción de un discurso nacional que superara las limitaciones que la palabra escrita tenía frente a la comunicación radial. La radio en el Perú, como medio, requirió de un proceso de adaptación: «puede decirse que existió un intervalo de tiempo en que no terminaban de acotarse ciertos usos sociales de dichos medios de comunicación» (Gutiérrez, 2008, p. 95).

Si bien la introducción de la radio y los receptores como un elemento más del hogar y de la vida cotidiana, no fue inmediato: «la radiodifusora nacional OAX4A fue empleada para llevar a la ciudadanía los discursos del mandatario, haciéndose uso entonces de parlantes ubicados en lugares públicos con el fin de aumentar la audiencia del medio» (Bustamante Quiroz, 2012, p. 34). El alto costo de los primeros receptores y el pago de los derechos de antena que la Peruvian Broadcasting intentaba institucionalizar para solventar su funcionamiento hicieron que el periodo temprano de la radio peruana se encontrara condicionado por la capacidad adquisitiva de la población y estuviera, por lo tanto, solo al alcance del público pudiente. La radio en el Perú nacería entonces como un proyecto privado y no comercial. La Peruvian Broadcasting intentó convertirla en un modelo privado comercial ${ }^{22}$ que controlara las emisiones y la familia

20 «Durante su primer año, OAX fue una radio que solo trasmitía tres horas diarias. Entre las 21:00 y 23:00 horas se mezclaba música, charlas, narraciones de personajes y los primeros teatros radiales» (Merayo Pérez, 2007, p. 330).

21 En el discurso inaugural, Leguía declaraba que «la inauguración de este servicio de radiodifusión es la prueba más concluyente de que el progreso del Perú marcha a grandes pasos» (Alegría, 1988, p. 31).

22 «Como el nacimiento de la radio en el Perú fue producto de un trabajo empresarial, la Peruvian Broadcasting Company abrió una tienda de receptores e hizo los primeros intentos de comercializarlos» (Merayo Pérez, 2007, p. 330). 
tecnológica de la radio ${ }^{23}$ y para ello acaparó la comercialización exclusiva de los aparatos de radio y ofreció el servicio correspondiente.

Vistas las potencialidades de uso político del nuevo medio para la construcción de una identidad nacional, el régimen de Leguía lo sustrajo del control de los radioaficionados al amparo del convenio de 1921, que consideraba los servicios nacionales de correos y telégrafos como monopolios estatales y al contrato ley de 1926 (Ley 5363), que consolidaba la exclusividad del servicio de radiocomunicaciones a los inversionistas ingleses de la compañía Marconi.

\section{Conclusiones}

La radio en el Perú, como medio, y al igual que lo que sucedía en los demás Estados sudamericanos, requirió de un proceso de adaptación que se vio facilitado por los antecedentes tecnológicos tempranos de la radiodifusión. La Patria Nueva, el proyecto modernizador del Oncenio, tuvo en cuenta este nuevo medio y no dudó en utilizarlo para la difusión de los valores de un recién descubierto nacionalismo criollo y andino, cuya raíz radicaba en el indigenismo. La proximidad del plebiscito de 1929 aceleró la construcción de este nuevo espacio de negociación. La producción radial pasó a ser controlada por el régimen leguiista, mediante la creación de la emisora Radio Nacional como institución estatal. Las primeras emisiones y las primeras programaciones radiales tuvieron, a instancias del régimen, un marcado carácter nacional, con el fin de construir una nueva identidad nacional.

La radio como nuevo espacio de negociación permitió construir una nueva identidad nacional a partir de un imaginario de lo que debía ser la música nacional peruana, partiendo de los gustos y expresiones musicales urbanas, especialmente y originalmente limeñas. En cuanto a los usos sociales de la radio durante el Oncenio, músicos criollos como los Montes y Manrique ya habían penetrado en la esfera doméstica mediante los cilindros y discos de los fonógrafos y gramófonos presentes en Lima desde fines del siglo XIX, y consolidaron, en el imaginario popular, a la música criolla como representativa de una música identitaria nacional peruana.

23 Siendo modelos construidos por aficionados, una búsqueda más intensa en los archivos permitiría descubrir las características y limitaciones técnicas. En Latinoamérica, Argentina tiene una vida técnica de la radio más temprana: en la década de 1920 ya se fabricaban y comercializan receptores hechos en el país. 


\section{REFERENCIAS BIBLIOGRÁFICAS}

Alegría, A. (1988). OAX. Crónica de la radio en el Perú (1925-1990). Lima: Radio Programas.

Anda y Ramos, F. (1997). La radio. El despertar del gigante. Ciudad de México: Editorial Trillas.

Bustamante Quiroz, E. (2012). La radio en el Perú. Lima: Fondo Editorial de la Universidad de Lima.

De Fleur, M. (1976). Teorías de la comunicación masiva. Buenos Aires: Paidós.

Gamarra, A. (El Tunante) (1907). Lima. Unos cuantos barrios y unos cuantos tipos (al comenzar el siglo XX). Lima: Litografía y Tipografía Nacional de Pedro Berrio.

Equipo Fénix (1996). La radio. Barcelona: Editorial RosaLjai.

El Comercio (1925-1930).

Fernández, J. L. (2008). La construcción de lo radiofónico (Dir.) Buenos Aires: La Crujía.

(2008). Acumulación y transformación en el surgimiento de los medios de sonido. Letra Imagen Sonido, Ciudad mediatizada, año l, nro. 1.

Gargurevich, J. (1989). La Peruvian Broadcasting Co. Historia de la radio (I). Lima: La Voz Ediciones.

Gernsback, H. (1919). Radio Amateur News. Nueva York: Experimenter Publishing Co.

(1922). Radio for All. Filadelfia: Lippincott Company.

González Miranda, S. (2004). El dios cautivo. Las ligas patrióticas en la chilenización compulsiva de Tarapacá (1910-1922). Santiago de Chile: LOM Ediciones.

Gutiérrez, M. (2008). Dispositivo radiofónico y vida cotidiana en los inicios de la radiodifusión. En J. L. Fernández, La construcción de lo radiofónico (pp. 91-107). Buenos Aires: La Crujía.

Harris, P. (1922). Crystal receivers for broadcast reception. Londres: The Wireless Press, Ltd.

Klaren, P. (2012). Nación y sociedad en la historia del Perú. Lima: Instituto de Estudios Peruanos.

Maskrey, A. y Rochabrún, G. (Eds.) (1990). Si Dios hizo la noche sin luz. El manejo popular de tecnologías. Lima: ITDG. 
Mendoza, Z. (2006). La hora del charango. Sentimiento cholo, cuzqueñidad y peruanidad. En Z. S. Mendoza, Sentir lo nuestro. Folclor, identidad regional y nacional en el Cuzco, siglo XX. Lima: Fondo Editorial Pontificia Universidad Católica del Perú.

Merayo Pérez, A. (2007). La radio en Iberoamérica: evolución, diagnóstico, prospectiva. Sevilla: Comunicación Social.

Oyarce, J. (2007). Orígenes del periodismo radial en el Perú I, sur: Arequipa, Cusco, Moquegua, Tacna y Puno. Lima: Fondo Editorial de la Universidad de San Martin de Porres. Orton, J. (2006). The Story of Semiconductors. Oxford y New York: Oxford University Press.

Radiola Guy (s. f.). Stromberg-Carlson 1-A. Recuperado de http://www.radiolaguy.com/Showcase/Battery-20s/Stromberg_Carlson-1A.htm

Radiomuseum (s.f.). RE2. Recuperado de http://www.radiomuseum.org/r/ afra_re2_re_2.html

Ruiz Zeballos, A. (2001). La multitud, las subsistencias y el trabajo: Lima, 1890-1920. Lima: Fondo Editorial de la Pontificia Universidad Católica del Perú.

Steven Johannessen Antique Radio Gallery (s. f.). Stromberg-Carlson 1-A (2). Recuperado de http://stevenjohannessen.com/radios4. asp\#Stromberg-Carlson $1 \mathrm{~A} 2$

Tello, M. (1986). Televisión y radio en el Perú: políticas y control. Lima: Universidad de Lima.

Turino, T. (2003). Nationalism and Latin American Music: Selected Case Studies and Theoretical Considerations. Latin American Music Review / Revista de Música Latinoamericana, vol. 24, nro. 2.

Vargas Escalante, J. (1944). 40 años de radio en el Perú. Lima: Editorial Imprenta Lux. 